\title{
Photoluminescent Patterned Papers Resulting from Printings of Polymeric Nanoparticles Suspension
}

\author{
Pierre Sarrazin, ${ }^{1}$ Davide Beneventi, ${ }^{1}$ Aurore Denneulin, ${ }^{1}$ Olivier Stephan, ${ }^{2}$ \\ and Didier Chaussy ${ }^{1}$ \\ ${ }^{1}$ Laboratory of Pulp and Paper Science and Graphic Arts (LGP2), Grenoble Institute of Technology, 461 rue de la Papeterie, \\ BP65-38402 Saint Martin d'Hères, France \\ ${ }^{2}$ Laboratory of Spectrometry and Physics (LSP), Grenoble University, 140 Avenue de la Physique, \\ BP87-38402 Saint Martin d'Hères, France \\ Correspondence should be addressed to Didier Chaussy, didier.chaussy@efpg.inpg.fr
}

Received 23 October 2009; Accepted 21 February 2010

Academic Editor: Jinying Yuan

Copyright (๑) 2010 Pierre Sarrazin et al. This is an open access article distributed under the Creative Commons Attribution License, which permits unrestricted use, distribution, and reproduction in any medium, provided the original work is properly cited.

\begin{abstract}
The printability of a copolyfluorene-fluorenone (PFFO) photoluminescent nanoparticle aqueous suspension on commercial tracing paper was here investigated. The nanoparticles suspension was obtained by miniemulsification of a suitable preformed photoluminescent organic polymer. The structural, physicochemical, and rheological characteristics of the nanoparticles suspension were first studied before considering its printability by inkjet and flexography techniques. The native properties of the nanoparticles suspension revealed to be more suitable for inkjet printing which was successfully used to print photoluminescent patterns using a very low amount of PFFO.
\end{abstract}

\section{Introduction}

Since the middle of the last century the interest towards photoluminescent inks increased steadily either in the interior and packaging decorations (e.g., printing paper and cardboard) or mostly in the paper security sector $[1,2]$. In the last domain, inks are composed of chromophores which: (i) are not visible under solar light to provide printed images that can not be photocopied, (ii) are readable only under special environments (e.g., ultraviolet light), (iii) can be thermally erasable for rewriting [3]. The luminescence of the majority of these inks originates from pigments [2], metal complexes [3], or specific organic compounds [4]. In the last decade it was demonstrated that a new material class such as organic semiconductors can be used to achieve luminescence [5] offering new opportunities for light-emitting sources [6] and a multitude of other electronic devices. Especially organic conjugated polymers have an excellent processability, since they are soluble in common organic solvents when functionalized with side chains. Thus, conjugated polymer organic solutions were easily processed by spin- or drop-casting, screen-printing [7-9] or inkjet printing $[4,10-13]$ for the treatment of several kinds of surfaces.

To tune luminescent properties, sophisticated control of the polymer luminescence colour, efficiency, and chargetransport properties are required. The emission wavelength depends on the extent of conjugation/delocalization, and can be controlled by the modification of the configuration or conformation of the polymer and by interactions with the local environment. This can be achieved by grafting functional moieties such as electron donor or acceptor groups, which allow the modulation of the electronic structure of the conjugated backbone. Studies, focused on semiconducting polymer chemistry, showed that polymer backbone substitutions or copolymerisation with other active or no-active monomer allow controlling the final conducting property of the material [14]. Finally, electronic interactions between neighbouring polymer chains may lead to the creation of new excited state species (excimers) [15-18] which can be beneficial if they are emissive $[19,20]$ or detrimental if they are nonemissive [21]. Such strategies have already been 
2,7-dibromo-9, 9-di-n-tetradecylfluorene
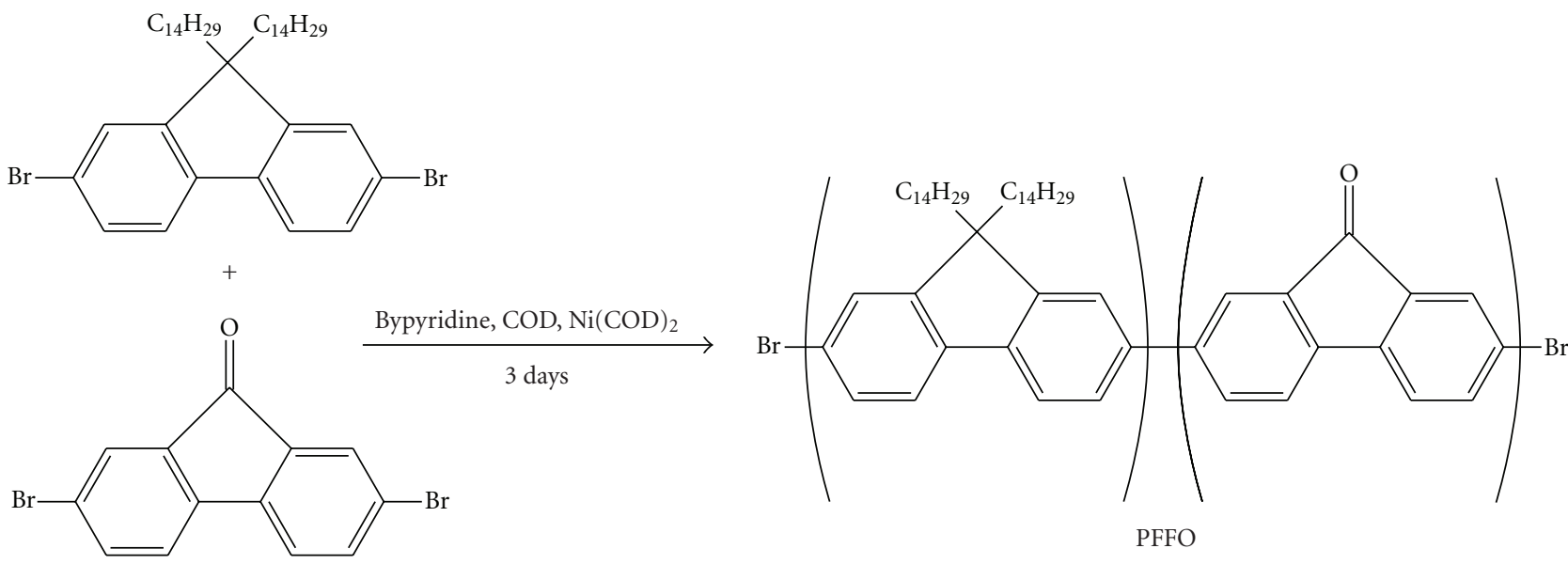

2,7-dibromofluorenone

FIgURE 1: Polymerisation of modified 2,7-dibromofluorene and 2,7-dibromofluorenone monomers by Yamamoto route.

reported to enhance the transport of energy and/or charge, thereby influencing or drastically changing the polymer performances [22].

In the paper industry, screen printing are relatively slow, limiting the productivity and use in high volume manufacturing [23]. For this reason high volume printing processes such as flexography are also typically used as contact deposition techniques. On an other hand, the inkjet printing process (technique without contact with the substrate) reveals several advantages for the deposition of precise material at well-defined positions.

Both printing processes require suitable ink characteristics such as: (i) solvent evaporation to optimize printing speed, (ii) rheology, surface tension and pigment size matching with printing device requirements. For these reasons, organic solvent-based inks were, for long time, the most employed. But, since the early 1980s, the overriding concern of inkmakers and printers has been the replacement the solvent by water. More precisely water-based emulsions are emerged as outstanding candidates to obtain very stable water-based ink which combine the intrinsic properties of the emulsified compound with those of nanostructured matter. Recently, several authors showed that aqueous organic conjugated polymer nanoparticles suspension exhibit unaltered luminescence properties and can be deposed on glassy or plastic substrates by inkjet printing in the manufacturing of thin film single and multilayer OLED or PLED [24-26]. At this time no studies are yet focused on the paper surface treatment by printing this kind of water-based nanoparticles suspension.

Basically, organic semiconducting polymer nanoparticles can be prepared by miniemulsion polymerization, where the monomer is polymerized to form polymer particles without changing the droplets identity [27]. Other possibilities are the formation of artificial latexes by reprecipitation of hydrophobic polymers in water $[28,29]$ or by solubilization of a preformed polymer in organic/aqueous mixtures and its miniemulsification in water to give stable emulsions with droplets size ranging between 50 and $500 \mathrm{~nm}$ [30, 31]. In the miniemulsification process, after evaporation of the solvent, a polymer dispersion is obtained in less restrictive conditions and without the presence of residual polymerisation byproducts.

A fairly recent investigation has shown that an orange 2,7-poly(9,9-dialkylfluorene-co-fluorenone) (PFFO) could be synthesized by Nickel(0) coupling (using the Yamamoto route) of the corresponding dibromo-monomers [32] (Figure 1) to obtain an efficient yellowish photoluminescence (PL) [33]. Previous studies showed that this polymer can be successfully miniemulsified to obtain aqueous particles suspension and these cationic nanoparticles are able to be adsorbed on cellulose fibres in one-step process to obtain bulky activated paper sheets $[34,35]$.

The purpose of this investigation was to show that a yellowish photoluminescent water-based ink can be formulated in one step by miniemulsification of a preformed polymer. As well as stable, free hazardous solvent, and easily handling, this nanoparticles suspension has the properties of inks commonly used in flexography and inkjet printing processes.

\section{Materials and Methods}

2.1. Materials. 2,7-dibromofluorene, 2,7-dibromofluorenone, sodium hydride, tetradecyl bromide, bipyridine and cyclooctadiene were provided by Aldrich. Tetradecyltrimethylammonium bromide (TTAB) was obtained from Fluka and $\operatorname{Bis}(1,5$-cyclooactadiene) $\operatorname{Nickel}(0)$ from Strem. Toluene, methanol, acetone, $\mathrm{HCl}, \mathrm{CHCl}_{3}, \mathrm{NaCl}, \mathrm{NaOH}$, and $\mathrm{N}, \mathrm{N}$-dimethylformamide used in experiments were of analytical grade.

A commercial tracing paper supplied by Clairefontaine was used as printing support. The grammage (mass per unit area) and thickness of tracing paper sheet were measured according to the norms ISO 534:2005 and ISO 536:1995, 
respectively. The surface topography (roughness) was estimated using the Parker Print Surf (PPS) instrument which measures the leakage of a low pressure air between the sample surface and the edge of the head reading ring. The PPS instrument operates using clamp at various pressure $(0.5,1$ or $2 \mathrm{MPa}$ ) which allows studying paper surface in function of the pressure to reach the roughness (in $\mu \mathrm{m}$ ). The porosity $(\varepsilon)$ of the tracing paper was estimated by using the following equation:

$$
\varepsilon=\frac{V_{\text {void }}}{V_{\text {tot }}}=\frac{V_{\text {tot }}-V_{\text {cell }}}{V_{\text {tot }}}=1-\frac{V_{\text {cell }} / w_{\text {sample }}}{V_{\text {tot }} / w_{\text {sample }}},
$$

where $w_{\text {sample }}$ is the sample weight, $V_{\text {tot }} / w_{\text {sample }}$ is the specific volume of the tracing paper and $V_{\text {cell }} / w_{\text {sample }}$ is the density of the solid part. As the tracing paper is composed only with cellulose fibres $\left(\rho_{\text {cell }}=1.54 \mathrm{~g} / \mathrm{cm}^{3}\right)$ :

$$
\frac{V_{\text {cell }}}{\mathrm{W}_{\text {sample }}}=\frac{1}{\rho_{\text {cell }}} \text {. }
$$

The surface energy of paper was obtained from contact angle measurements performed with a DataPhysics OCA20 using the sessile drop method. For that, the initial resting drop image was acquired by a CDD camera and the corresponding contact angle was calculated after fitting the drop contour line to an ellipse. To determine the surface energy four liquids were used as probe: demineralised water, glycerol, ethylene glycol, and diiodomethane. By applying the Owens, Wendt, Kaelbe and Uy (OWKU) approximation of the dispersive and the polar interactions between the two phases by a geometric mean expression, the surface energy was calculated as the sum of the dispersive and polar solid surface energies.

2.2. Synthesis of the Photoluminescent Polymer. The monomer was synthesised starting from $10 \mathrm{mmol}$ of 2,7-dibromofluorene dissolved in $50 \mathrm{~mL}$ of N,N-dimethylformamide. $20 \mathrm{mmol}$ of sodium hydride was added to the mixture at room temperature. After 4 hours under stirring, $30 \mathrm{mmol}$ of tetradecyl bromide were slowly added and the mixture stirred for an additional period of 12 hours. Then, the 2,7-dibromo-9,9-di-n tetradecylfluorene was purified by column chromatography using pentane as eluant. The copolymer was synthesised by mixing 2,7-dibromo-9,9-di-n-tetradecylfluorene ( $1.8 \mathrm{mmol})$ and 2,7-dibromofluorenone $(0.2 \mathrm{mmol})$, Bipyridine $(2 \mathrm{mmol})$, cyclooctadiene $(2.5 \mathrm{mmol})$ and Bis $(1,5$-cyclooctadiene)Nickel(0) (2 mmol) (Figure 1). Toluene (16 mL) and N,Ndimethylformamide $(6 \mathrm{~mL})$ were added via syringe and the mixture was stirred at $80^{\circ} \mathrm{C}$ for 3 days. After cooling the polymer was precipitated by pouring the solution in a methanolacetone-concentrated $\mathrm{HCl}$ mixture. The solid was collected by filtration and purified by subsequent precipitation in methanol mixture.

\subsection{Preparation of the Aqueous Nanoparticles Suspension.} The synthesised copolyfluorene-fluorenone, PFFO, (10 mg) was dissolved in $1 \mathrm{~mL} \mathrm{CHCl}_{3}(\mathrm{CF})$ and added to $5 \mathrm{~mL}$ of an

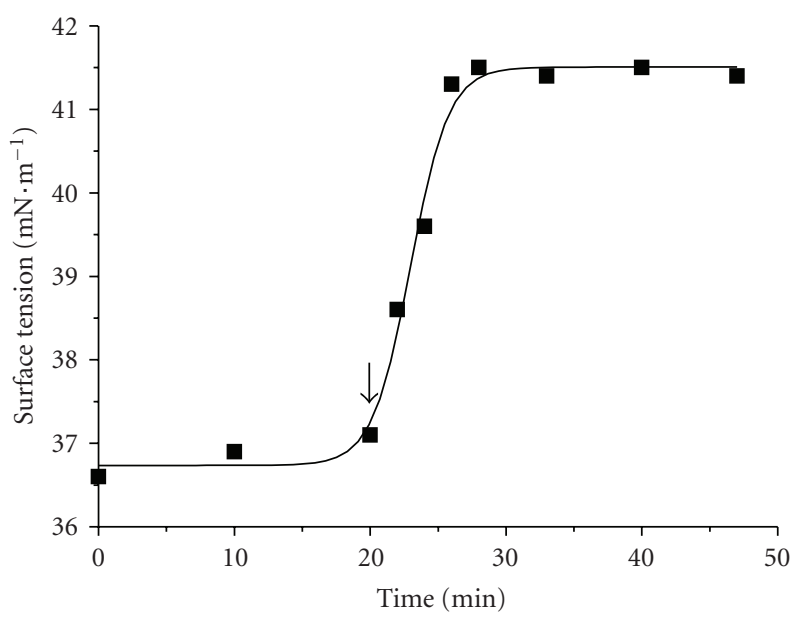

(a)

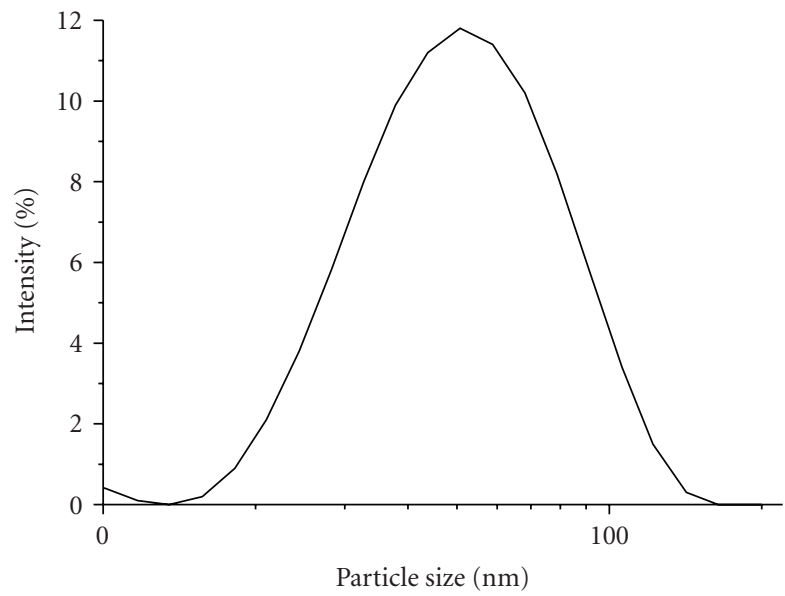

(b)

FIGURE 2: (a) Variation of the surface tension of water-TTAB-PFFOCF systems during ultrasonication (arrow indicates the beginning of ultrasonication). (b) Intensity weighed particle size distribution of PFFO nanoparticles.

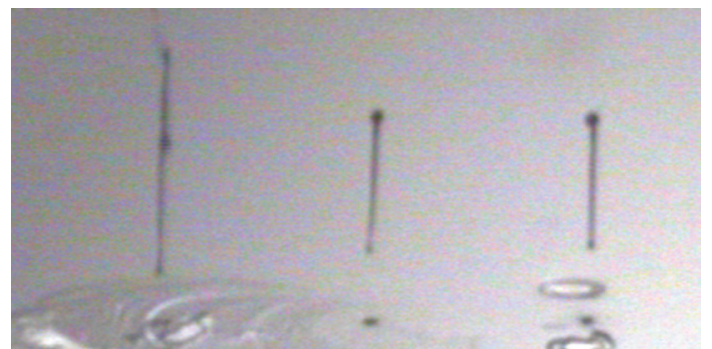

FIGURE 3: Inkjet drop formation of the PFFO nanoparticles suspension.

aqueous Tetradecyltrimethylammonium bromide (TTAB) (17 mg, 6 times higher than c.m.c) solution. After stirring 15 minutes for pre-emulsification, the miniemulsion was prepared by ultrasonicating the mixture for 15 minutes (bath, $150 \mathrm{~W}$ ). After ultrasonication, the sample was stirred in a regulated bath at $50^{\circ} \mathrm{C}$ for 30 minutes to evaporate the 


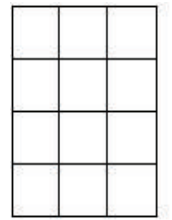

$1 \mathrm{~cm}$
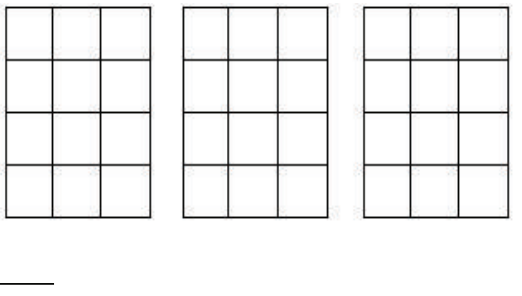

(a)

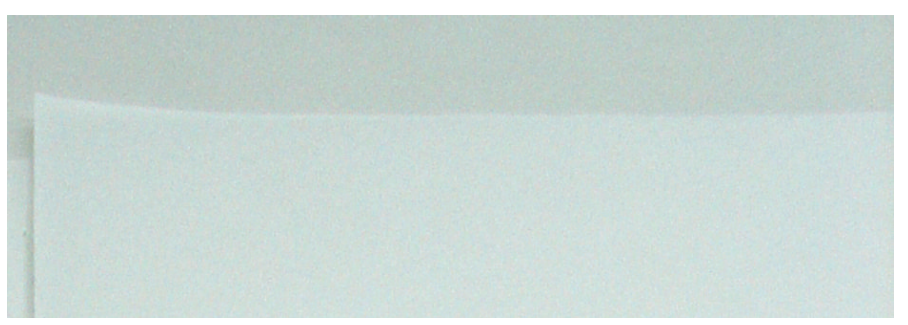

(c)

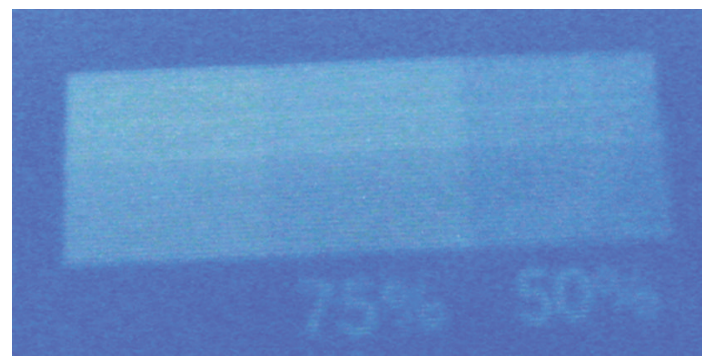

(e)

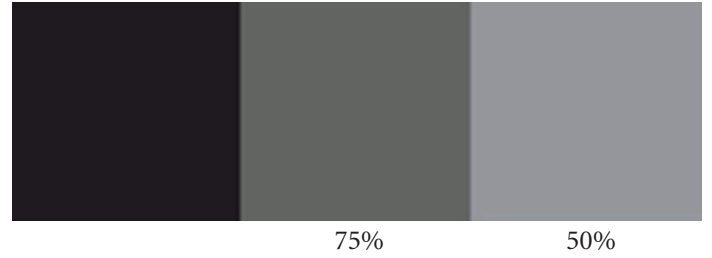

$1 \mathrm{~cm}$

(b)

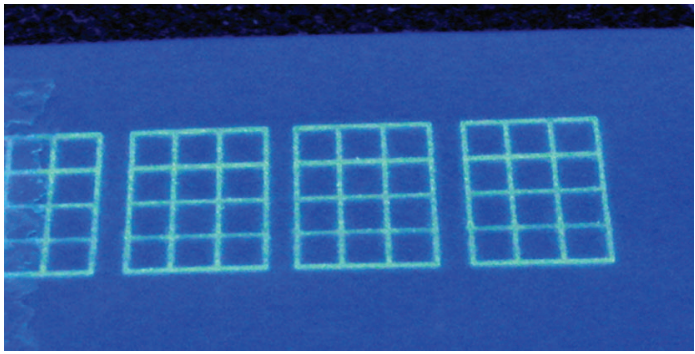

(d)

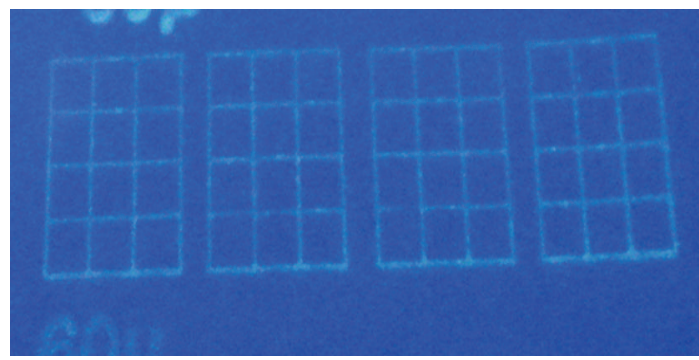

(f)

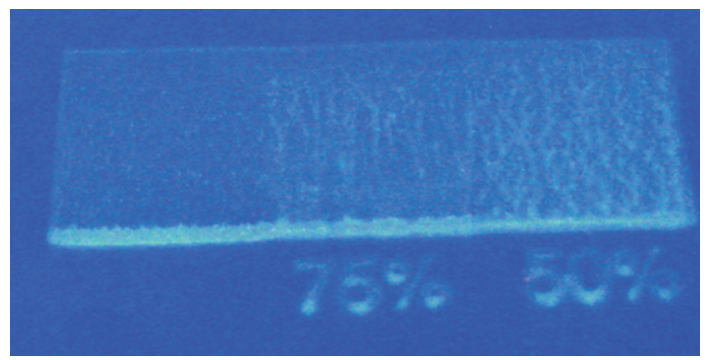

(g)

FIgURE 4: Printed patterns: grids of squares (a), full tones (b); printed tracing paper under room light (c); inkjet printed patterns under UV-light ( $\mathrm{d}$ and e); flexography printed patterns under UV-light (f and $\mathrm{g}$ ).

$\mathrm{CHCl}_{3}$. The polymer particles size was cut off at $1.2 \mu \mathrm{m}$ by filtrating the solution using a $1.2 \mu \mathrm{m}$ syringe filter.

The Zeta-potential and the intensity weighted particle size distribution of photoluminescent PFFO particles were measured by electrophoresis and dynamic light scattering (DLS) (Malvern Zetasizer nanoZS) in a $10^{-2} \mathrm{M} \mathrm{NaCl}$ solution. The surface tension of the PFFO particles suspension was measured using the Wilhelmy plate technique (Kruss, K 100, Germany). The viscosity of the PFFO nanoparticles suspension was determined with a rheometer (Anton Paar, Physica MCR 301) measuring the evolution of the shear stress $(\mathrm{Pa})$ in function of the shear rate $\left(0-1500 \mathrm{~s}^{-1}\right)$.
2.4. Inkjet and Flexography Printings. The same pattern was printed by inkjet and flexography. For inkjet process the drop and demand (DOD) technology was applied and the PFFO nanoparticles suspension was printed onto tracing paper samples using a laboratory piezoelectric inkjet printer (Fujifilm-Dimatix DMP 2831 with 10 pL nominal drop size cartridge). Jetting of the fluid was controlled by a voltage pulse to deform the piezoelectric actuator in the ink cavity and eject a drop from the nozzle. A drop-watch camera included in the printer allowed checking the jettability of fluids. Flexography printing was realised with a Flexiproof 100 device supplied by RK Print Coat Instruments. This printing 


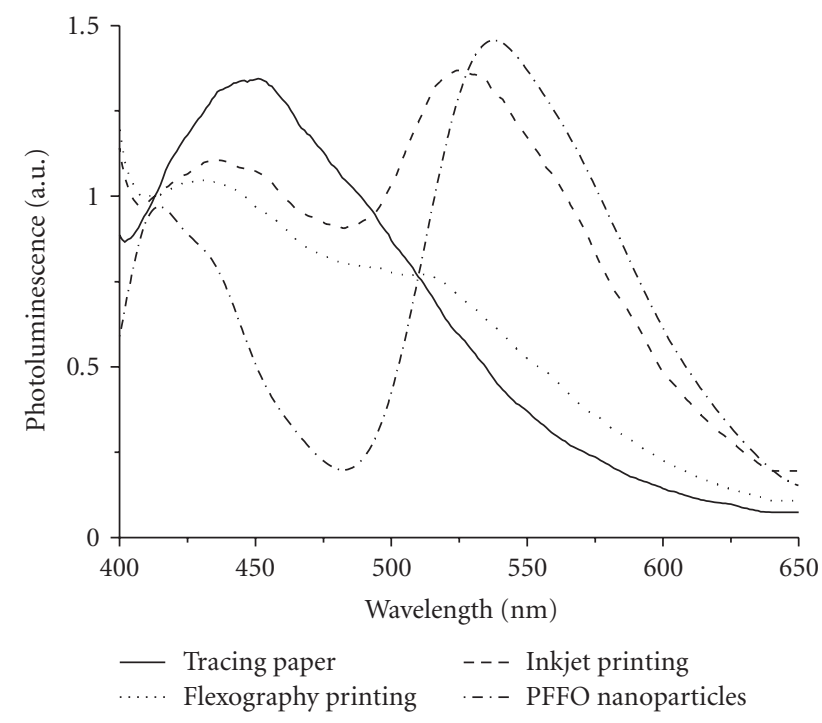

Figure 5: Photoluminescence of full tone printed patterns and PFFO nanoparticles suspension.

process is based on a rotary relief method of printing. The image pattern plate made of rubber or plastic is attached to a plate cylinder. Ink is applied to the printing plate using an engraved roller called anilox. Printing experiments were realised on paper strips of $105 \times 297 \mathrm{~cm}$, with an anilox of $5 \mathrm{~cm}^{3} / \mathrm{m}^{2}$ and a print speed of $25 \mathrm{~m} / \mathrm{min}$. The pressure of the anilox on the printing plate and the pressure of the printing plate on the paper were progressively modified by changing the position between elements by $4 \mu \mathrm{m}$ incrementation.

Printed pattern morphology and the water stability of printings were studied using a Zeiss Axiovert 200 confocal laser scanning microscope. Photoluminescence measurements of printed area were performed using a spectrofluorometer (Fluorolog, Horiba Jobin Yvon) after an excitation at $365 \mathrm{~nm}$. Photoluminescence spectra were recorded at room temperature and ambient atmosphere.

\section{Results and Discussion}

3.1. Polymer, Ink, and Support Preparations. The photoluminescent copolyfluorene-fluorenone (PFFO) was obtained with a reactive yield around $40 \%$. This polymer is mainly amorphous $\left(\mathrm{Tg}=-20^{\circ} \mathrm{C}\right)$ with a liquid crystal transition at $45^{\circ} \mathrm{C}$. The solution of the polymer in chloroform (CF) was successfully miniemulsified in water by using an excess (8 times $\mathrm{cmc}$ ) of tetradecyltrimethylammonium bromide (TTAB) to obtain a photoluminescent yellowish nanoparticles suspension. Surface tension measurements taken during the miniemulsification process showed an initial increase in surface tension from 36.8 to $41.6 \mathrm{mN} \cdot \mathrm{m}^{-1}$ followed by a plateau, which reflected the progressive TTAB adsorption to the surface of freshly formed PFFO/chloroform droplets (Figure 2(a)). Even after prolonged ultrasonication, surface tension remained constant indicating that after 6 minutes ultrasonication TTAB adsorption reached the equilibrium and therefore that free surfactant remains in the aqueous phase with a concentration close to the c.m.c. At this concentration, the final PFFO nanoparticle suspension is stabilized by the strong positive charge associated to the presence of adsorbed surfactants on particles surface. DLS measurements showed an intensity weighed particle size distribution centered on $60 \mathrm{~nm}$ with bigger particles closed to $200 \mathrm{~nm}$ (Figure 2(b)). The surface tension and particle size values suggested, according to several previous studies [25, 36-39], that the PFFO nanoparticles suspension prepared by miniemulsification seems to have intrinsically suitable properties to be printed with inkjet printing process. Besides the nanoparticles suspension showed a Newtonian behaviour and a low viscosity of $1.12 \mathrm{mPa} \cdot \mathrm{s}^{-1}$, which is necessary in flexography printing process for which the ink needs to flow into the cells of the anilox rolls of the press (Table 1).

The surface analysis of the tracing paper (thickness = $68 \mu \mathrm{m})$ with Parker Print Surf instrument confirmed its low roughness $(5.7 \mu \mathrm{m})$. The estimated porosity revealed the slight porous $(32 \%)$ structure of this $71.5 \mathrm{~g} / \mathrm{m}^{2}$ density fibres sheet. Finally the surface energy of the paper was estimated from the measurement of the contact angle between several liquids and the support (Table 1). It had a polar component of $5.7 \mathrm{mN} \cdot \mathrm{m}^{-1}$ and a dispersive one of $31.2 \mathrm{mN} \cdot \mathrm{m}^{-1}$. The low roughness and the rather hydrophobic surface of this support allowed assuming that during the printing process this support should be treated only on the surface because of the difficulty of the water-based ink to penetrate in the paper. The contact angle of the native PFFO nanoparticles suspension on the tracing paper $\left(67.1^{\circ}\right)$ was lower than with water $\left(90.4^{\circ}\right)$ (Table 1$)$. It is attributed to the presence of free surfactant molecules which decrease the surface tension of the miniemulsion and improve its spreading onto the support.

3.2. Printing. With inkjet printing system, the aqueous dispersion was directly DOD inkjet printed by applying the Dymatix printer parameters used during previous investigations realised by co-workers with a similar water-based ink [40].

Figure 3 displays the droplet formation of the PFFO nanoparticles suspension printed by the three nozzles printer. During the ejection, the droplet forms a thread before droplet detaches the nozzle. This phenomenon can be associated, in comparison with some other investigations, to the bead-on-a-string effect of a polymer-based solution used as ink $[25,41]$. Nevertheless, the inkjet printing process remained stable during the entire paper treatment meaning that the formation of the droplet does not alter with time and that the native suspension has almost suitable ink properties (e.g., viscosity, surface tension).

With the flexography process, before processing to the printing of the native PFFO nanoparticles suspension, printing parameters of the Flexiproof device were optimized with a commercial blue water-based ink. Experiments showed that, for one millilitre of ink, the highest pressure of the anilox on the printing plate and the highest pressure of the printing plate on the paper were required to print patterns without deforming the printing plate. 


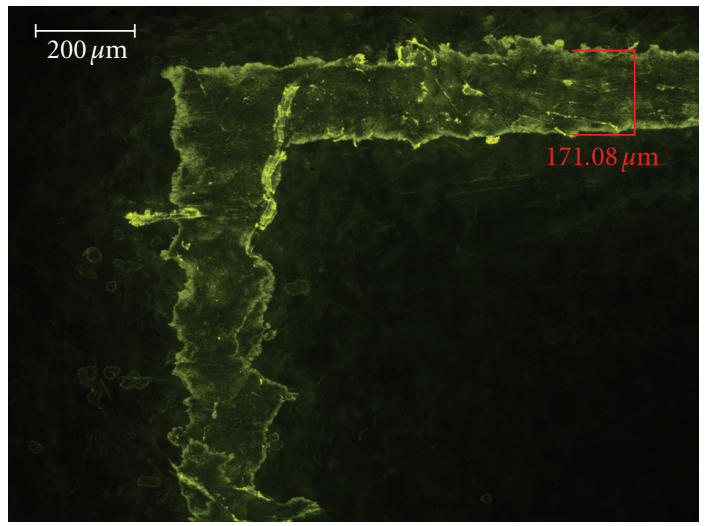

(a)

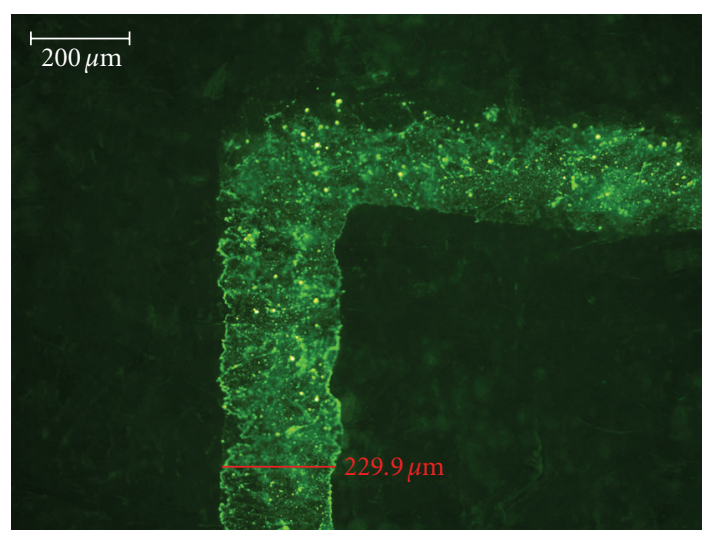

(c)

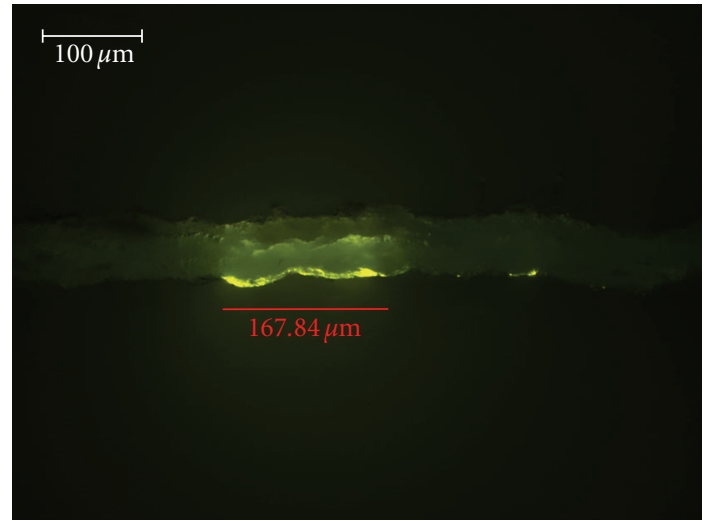

(b)

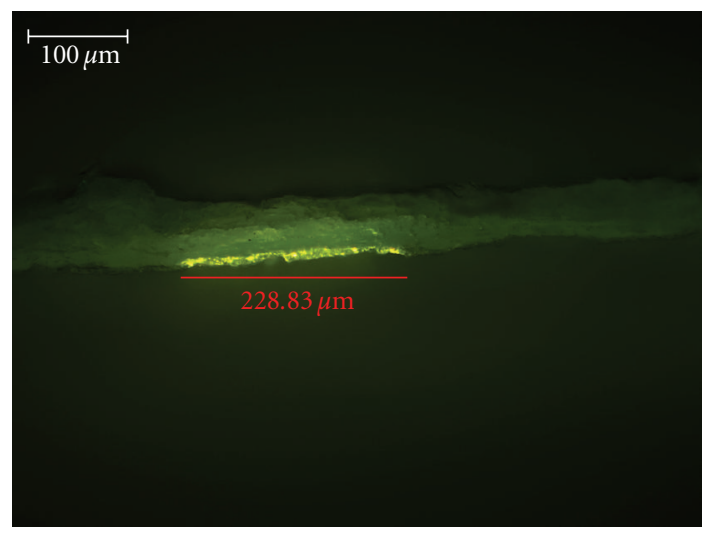

(d)

FIGURE 6: Fluorescence microscopy pictures of one right angle and of the slide of printed square on the tracing paper. Inkjet printing (a and b); Flexography (c and d).

TABLE 1: Ink and support characteristics.

Ink

\begin{tabular}{|c|c|c|c|c|c|}
\hline \multirow[b]{2}{*}{ Viscosity $\left(\mathrm{mPa} \cdot \mathrm{s}^{-1}\right)$} & \multirow[b]{2}{*}{$\begin{array}{l}\text { Surface Tension } \\
\left(\mathrm{mN} \cdot \mathrm{m}^{-1}\right)\end{array}$} & \multirow[b]{2}{*}{ Roughness PPS $(\mu \mathrm{m})$} & \multirow[b]{2}{*}{$\begin{array}{l}\text { Surface Energy } \\
\left(\mathrm{mN} \cdot \mathrm{m}^{-1}\right)\end{array}$} & \multicolumn{2}{|c|}{ Contact Angle $\left(\mathrm{deg}^{\circ}\right)$} \\
\hline & & & & Water & $\begin{array}{l}\text { PFFO } \\
\text { nanoparticles } \\
\text { suspension }\end{array}$ \\
\hline 1.12 & 41.5 & 5.7 & 36.9 & 90.4 & 67.1 \\
\hline
\end{tabular}

After studying the efficiency of the ejected drop in inkjet printing (jettability performance) and optimizing the transfer conditions in flexography process, the interaction between the printed nanoparticles suspension and the substrate was taken under consideration. In both printing processes, one millilitre of PFFO nanoparticles suspension was used to print two different patterns such as grids of 12 squares and full tone (Figures $4(\mathrm{a})$ and $4(\mathrm{~b})$ ). The printed patterns were room air dried after less than two minutes before their characterisation. Camera pictures of the treated paper under UV-light showed globally an efficient photoluminescence of printed patterns by flexography and inkjet printing whereas nothing appeared under room light (Figures 4(c), 4(d), 4(e), 4(f), 4(g)). Photoluminescent PFFO nanoparticles were successfully deposit on the tracing paper because of their affinity with the negative charged cellulose fibres surface due to their positive surface charge provided by cationic surfactant $[34,35]$. As demonstrated in these latter investigations, the adsorption of PFFO nanoparticles on the cellulose fibre surface of the tracing paper remains stable even the prolonged wetting of the printed paper ( 1 minute) in deionised water.

Concerning flexography printed full tone pattern, nanoparticles accumulation occurred at the bottom of the model (Figure 4(g)) assuming an inhomogeneous pressure of the printing plate either on the anilox or on the paper itself. Whereas, with inkjet printing, a more homogeneous (no ink accumulation) printed pattern was obtained (Figure 4(e)). It seems that the horizontal treatment of the tracing paper by a technique without contact between the substrate and a 
low viscosity ink is more suitable. Figure 5 shows that the commercial tracing paper has a native photoluminescence in the UV-visible blue region whereas the $100 \%$ full tone printed areas have a yellowish photoluminescence corresponding to the activity of PFFO nanoparticles deposited on tracing paper surface. Because of the contribution of the tracing paper, the photoluminescence of these both patterns was slightly shifted to the bluish region. Inkjet printed full tone displayed a higher photoluminescence than those obtained by flexography because the flexography technique led to a heterogeneous printed pattern with a lower amount of nanoparticles spread out on the studied surface.

In both cases, fluorescence microscopy pictures showed that the grids of squares were printed with a similar film thickness (around $8 \mu \mathrm{m}$ ) but with a more homogeneous film morphology with the inkjet technique (Figure 6). Furthermore, the line width of squares was 3 and 4 times higher for inkjet and flexography, respectively, than the designed pattern on the polymeric printing plate $(\approx 60 \mu \mathrm{m})$. For flexography, this difference was ascribed to the high pressure used between the printing plate and the paper which led to the compression and deformation of the printing plate on the support. Whereas for inkjet printing this gap can come from the spreading of suspension droplets on the substrate $\left(\right.$ contact angle $\left.=67.1^{\circ}\right)$. To understand more efficiently these phenomena and to control the printed pattern aspects (pattern size and photoluminescence intensity), the influence of PFFO nanoparticles suspension characteristics (nanoparticles size and concentration) and printing processes parameters (e.g., jet frequency or ink volume) is currently yet deeply studied.

\section{Conclusion}

In summary, we have pointed out that a photoluminescent nanoparticles suspension obtained by miniemulsification of preformed semiconducting polymer (PFFO) can be used as an effective water-based ink for paper treatment. This suspension was suited to inkjet or flexography printing techniques because it is composed of nanosized "pigments" (nanoparticles) and it showed suitable properties such as low viscosity $\left(\sim 1 \mathrm{mPa} \cdot \mathrm{s}^{-1}\right)$ and surface tension $\left(\sim 40 \mathrm{mN} \cdot \mathrm{m}^{-1}\right)$. The better printed patterned tracing papers (printed shape, photoluminescence quality, etc.) were obtained with the inkjet process with a lower amount of PFFO nanoparticles suspension. However, a thorough survey of the parameters of the printing process is necessary to consider the use of this specific ink in different domains such as security papers.

\section{Acknowledgments}

The authors wish to thank the microscopy team workers of the LGP2 laboratory for their expertise in taking fluorescence imaging measurements. This work was supported by a MEN Grant.

\section{References}

[1] R. W. Phillips and A. F. Bleikolm, "Optical coatings for document security," Applied Optics, vol. 35, no. 28, pp. 55295534, 1996.

[2] M. Yousaf and M. Lazzouni, "Formulation of an invisible infrared printing ink," Dyes and Pigments, vol. 27, no. 4, pp. 297-303, 1995.

[3] A. Kishimura, T. Yamashita, K. Yamaguchi, and T. Aida, "Rewritable phosphorescent paper by the control of competing kinetic and thermodynamic self-assembling events," Nature Materials, vol. 4, no. 7, pp. 546-549, 2005.

[4] T. R. Hebner, C. C. Wu, D. Marcy, M. H. Lu, and J. C. Sturm, "Ink-jet printing of doped polymers for organic light emitting devices," Applied Physics Letters, vol. 72, no. 5, pp. 519-521, 1998.

[5] M. Pope, H. P. Kallmann, and P. Magnante, "Electroluminescence in organic crystals," The Journal of Chemical Physics, vol. 38, no. 8, pp. 2042-2043, 1963.

[6] R. H. Friend, R. W. Gymer, A. B. Holmes, et al., "Electroluminescence in conjugated polymers," Nature, vol. 397, no. 6715, pp. 121-128, 1999.

[7] Z. Bao, Y. Feng, A. Dodabalapur, V. R. Raju, and A. J. Lovinger, "High-performance plastic transistors fabricated by printing techniques," Chemistry of Materials, vol. 9, no. 6, pp. 12991301, 1997.

[8] K. Mori, T. Ning, M. Ichikawa, T. Koyama, and Y. Taniguchi, "Organic light-emitting devices patterned by screen-printing," Japanese Journal of Applied Physics, vol. 39, no. 9, pp. L942L944, 2000.

[9] S. E. Shaheen, R. Radspinner, N. Peyghambarian, and G. E. Jabbour, "Fabrication of bulk heterojunction plastic solar cells by screen printing," Applied Physics Letters, vol. 79, no. 18, pp. 2996-2998, 2001.

[10] T. R. Hebner and J. C. Sturm, "Local tuning of organic lightemitting diode color by dye droplet application," Applied Physics Letters, vol. 73, no. 13, pp. 1775-1777, 1998.

[11] L. M. Leung, C. F. Kwong, C. C. Kwok, and S. K. So, "Organic polymer thick film light emitting diodes (PTFOLED),” Displays, vol. 21, no. 5, pp. 199-201, 2000.

[12] Y. Yang, S.-C. Chang, J. Bharathan, and J. Liu, "Organic/polymeric electroluminescent devices processed by hybrid ink-jet printing," Journal of Materials Science: Materials in Electronics, vol. 11, no. 2, pp. 89-96, 2000.

[13] C. N. Hoth, S. A. Choulis, P. Schilinsky, and C. J. Brabec, "High photovoltaic performance of inkjet printed polymer:fullerene blends," Advanced Materials, vol. 19, no. 22, pp. 3973-3978, 2007.

[14] X. Qiao, X. Wang, and Z. Mo, "Effects of different alkyl substitution on the structures and properties of poly(3alkylthiophenes)," Synthetic Metals, vol. 118, no. 1-3, pp. 8995, 2001.

[15] M. Yan, L. J. Rothberg, E. W. Kwock, and T. M. Miller, "Interchain excitations in conjugated polymers," Physical Review Letters, vol. 75, no. 10, pp. 1992-1995, 1995.

[16] C. L. Chochos, J. K. Kallitsis, and V. G. Gregoriou, "Rodcoil block copolymers incorporating terfluorene segments for stable blue light emission," The Journal of Physical Chemistry $B$, vol. 109, no. 18, pp. 8755-8760, 2005.

[17] C. L. Chochos, D. Papakonstandopoulou, S. P. Economopoulos, V. G. Gregoriou, and J. K. Kallitsis, "Synthesis and optical properties on a series of polyethers incorporating terfluorene segments and methylene spacers," Journal of Macromolecular Science Part A, vol. 43, no. 3, pp. 419-431, 2006. 
[18] C. L. Chochos, N. P. Tzanetos, S. P. Economopoulos, V. G. Gregoriou, and J. K. Kallitsis, "Synthesis and characterization of random copolymers combining terfluorene segments and hole or electron transporting moieties," Journal of Macromolecular Science Part A, vol. 44, no. 9, pp. 923-930, 2007.

[19] M. W. Wu and E. M. Conwell, "Effect of interchain coupling on conducting polymer luminescence: excimers in derivatives of poly(phenylene vinylene)," Physical Review B, vol. 56, no. 16, pp. 10060-10062, 1997.

[20] C. L. Chochos, J. K. Kallitsis, P. E. Keivanidis, S. Baluschev, and V. G. Gregoriou, "Thermally stable blue emitting terfluorene block copolymers," The Journal of Physical Chemistry B, vol. 110, no. 10, pp. 4657-4662, 2006.

[21] R. Jakubiak, L. J. Rothberg, W. Wan, and B. R. Hsieh, "Reduction of photoluminescence quantum yield by interchain interactions in conjugated polymer films," Synthetic Metals, vol. 101, no. 1-3, pp. 230-233, 1999.

[22] T.-Q. Nguyen, I. B. Martini, J. Liu, and B. J. Schwartz, "Controlling interchain interactions in conjugated polymers: the effects of chain morphology on exciton-exciton annihilation and aggregation in MEH-PPV films," The Journal of Physical Chemistry B, vol. 104, no. 2, pp. 237-255, 2000.

[23] P. Calvert, "Inkjet printing for materials and devices," Chemistry of Materials, vol. 13, no. 10, pp. 3299-3305, 2001.

[24] E. Fisslthaler, S. Sax, U. Scherf, et al., "Inkjet printed polymer light-emitting devices fabricated by thermal embedding of semiconducting polymer nanospheres in an inert matrix," Applied Physics Letters, vol. 92, no. 18, Article ID 183305, 2008.

[25] G. Mauthner, K. Landfester, A. Köck, et al., "Inkjet printed surface cell light-emitting devices from a water-based polymer dispersion," Organic Electronics, vol. 9, no. 2, pp. 164-170, 2008.

[26] T. Piok, S. Gamerith, C. Gadermaier, et al., "Organic light-emitting devices fabricated from semiconducting nanospheres," Advanced Materials, vol. 15, no. 10, pp. 800-804, 2003.

[27] M. Omastová, M. Trchová, J. Kovarova, and J. Stejskal, "Synthesis and structural study of polypyrroles prepared in the presence of surfactants," Synthetic Metals, vol. 138, no. 3, pp. 447-455, 2003.

[28] F. Kong, X. L. Wu, G. S. Huang, R. K. Yuan, and P. K. Chu, "Tunable emission from composite polymer nanoparticles based on resonance energy transfer," Thin Solid Films, vol. 516, no. 18, pp. 6287-6292, 2008.

[29] M. Zhao, J. Li, E. Mano, et al., "Oxidation of primary alcohols to carboxylic acids with sodium chlorite catalyzed by TEMPO and bleach," Journal of Organic Chemistry, vol. 64, no. 7, pp. 2564-2566, 1999.

[30] M. Antonietti and K. Landfester, "Polyreactions in miniemulsions," Progress in Polymer Science, vol. 27, no. 4, pp. 689-757, 2002.

[31] K. Landfester, R. Montenegro, U. Scherf, et al., "Semiconducting polymer nanospheres in aqueous dispersion prepared by a miniemulsion process," Advanced Materials, vol. 14, no. 9, pp. 651-655, 2002.

[32] T. Yamamoto, A. Morita, Y. Miyazaki, et al., "Preparation of piconjugated poly(Thiophene-2,5-Diyl), poly(Para-Phenylene), and related polymers using zero valent nickel-complexeslinear structure and properties of the pi-conjugated polymers," Macromolecules, vol. 25, no. 4, pp. 1214-1223, 1992.

[33] S. Panozzo, J.-C. Vial, Y. Kervella, and O. Stéphan, "Fluorenefluorenone copolymer: stable and efficient yellow-emitting material for electroluminescent devices," Journal of Applied Physics, vol. 92, no. 7, pp. 3495-3502, 2002.
[34] P. Sarrazin, D. Beneventi, D. Chaussy, L. Vurth, and O. Stephan, "Adsorption of cationic photoluminescent nanoparticles on softwood cellulose fibres: effects of particles stabilization and fibres' beating," Colloids and Surfaces A, vol. 334, no. 1-3, pp. 80-86, 2009.

[35] P. Sarrazin, L. Valecce, D. Beneventi, D. Chaussy, L. Vurth, and O. Stephan, "Photoluminescent paper based on poly(fluoreneco-fluorenone) particles adsorption on modified cellulose fibers," Advanced Materials, vol. 19, no. 20, pp. 3291-3294, 2007.

[36] R. Mannerbro, M. Ranlöf, N. Robinson, and R. Forchheimer, "Inkjet printed electrochemical organic electronics," Synthetic Metals, vol. 158, no. 13, pp. 556-560, 2008.

[37] O. Ngamna, A. Morrin, A. J. Killard, S. E. Moulton, M. R. Smyth, and G. G. Wallace, "Inkjet printable polyaniline nanoformulations," Langmuir, vol. 23, no. 16, pp. 8569-8574, 2007.

[38] M. D. Croucher and M. L. Hair, "Design criteria and future directions in inkjet ink technology," Industrial and Engineering Chemistry Research, vol. 28, no. 11, pp. 1712-1718, 1989.

[39] B.-J. De Gans, E. Kazancioglu, W. Meyer, and U. S. Schubert, "Ink-jet printing polymers and polymer libraries using micropipettes," Macromolecular Rapid Communications, vol. 25, no. 1, pp. 292-296, 2004.

[40] A. Denneulin, J. Bras, A. Blayo, B. Khelifi, F. Roussel-Dherbey, and C. Neuman, "The influence of carbon nanotubes in inkjet printing of conductive polymer suspensions," Nanotechnology, vol. 20, no. 38, pp. 1-10, 2009.

[41] R. P. Mun, J. A. Byars, and D. V. Boger, "The effects of polymer concentration and molecular weight on the breakup of laminar capillary jets," Journal of Non-Newtonian Fluid Mechanics, vol. 74, no. 1-3, pp. 285-297, 1998. 

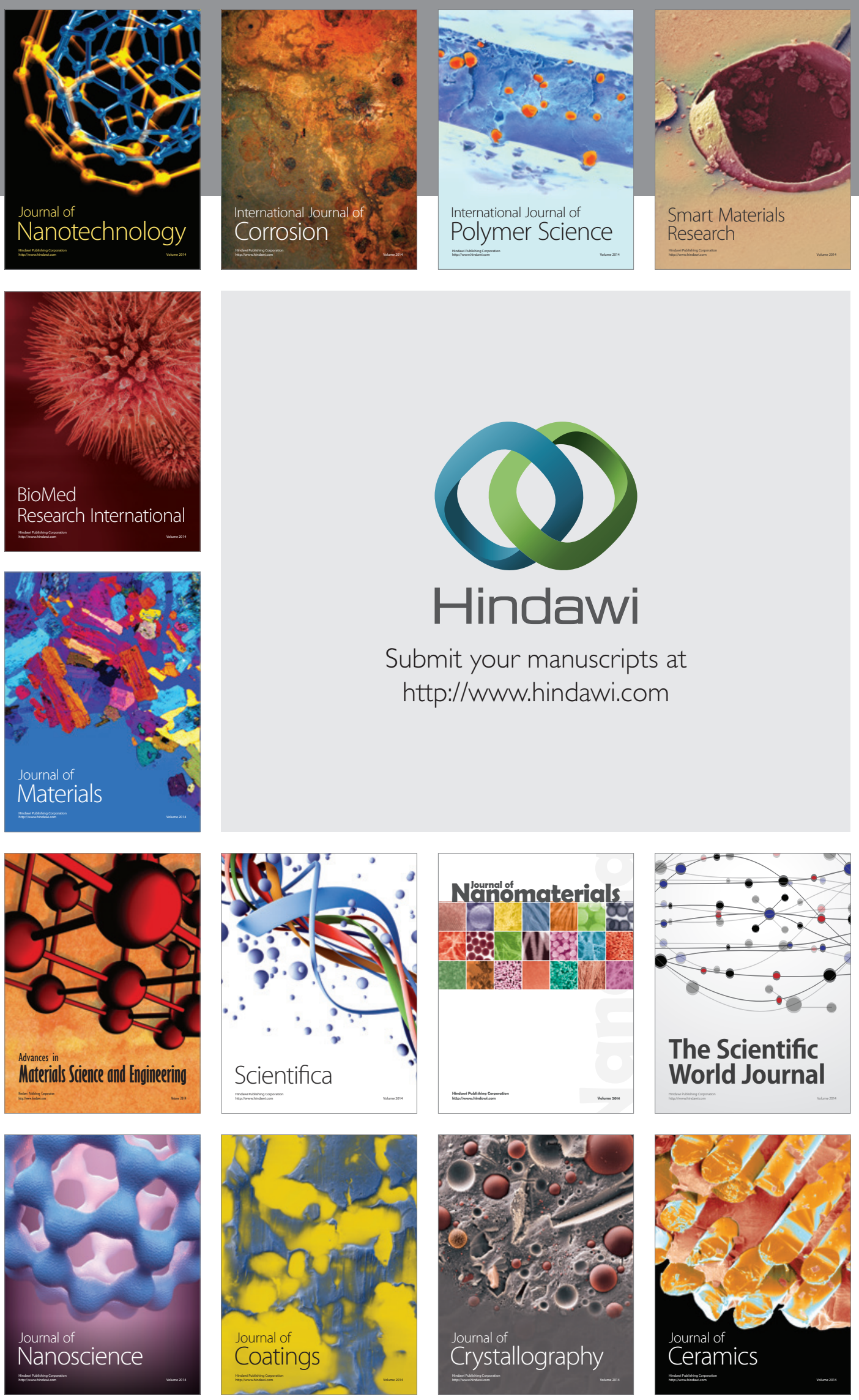

The Scientific World Journal

Submit your manuscripts at

http://www.hindawi.com

\section{World Journal}

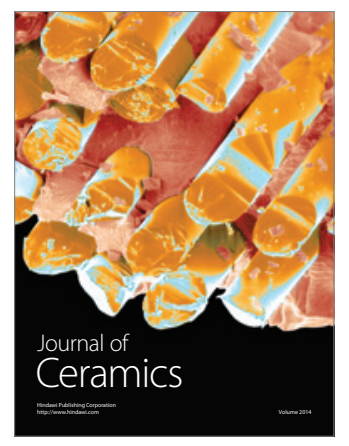

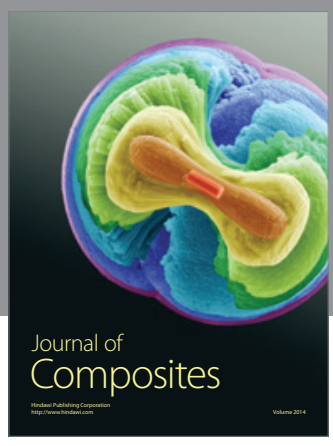
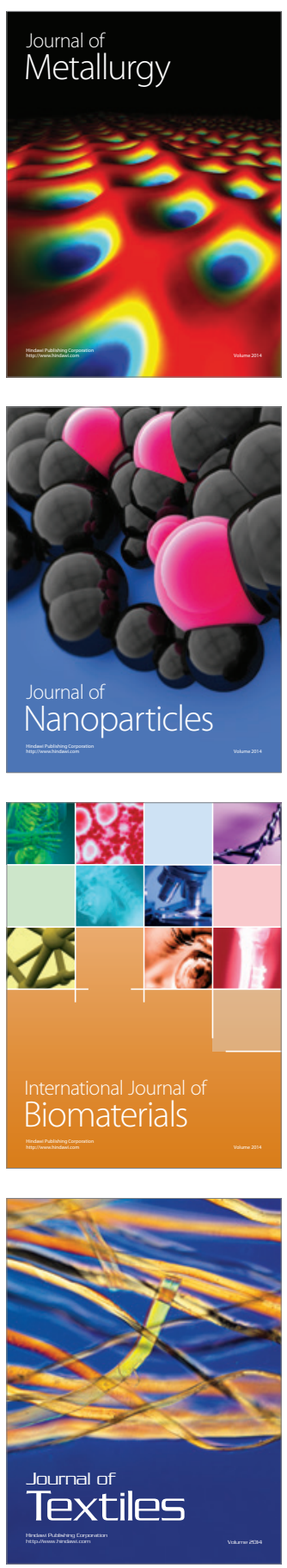